\title{
A ginástica vai à escola ${ }^{1}$
}

Laurita Schiavon* Vilma L. Nista-Piccolo**

\begin{abstract}
Resumo: A partir de estudos que têm como foco de investigação as razões da ausência da Ginástica na escola, realizou-se uma pesquisa em instituições de ensino formal da Diretoria de ensino de Campinas (SP), para verificar até que ponto o quadro diagnóstico encontrado é o mesmo desenhado pelas conclusões apresentadas nesses estudos. O que se pretendeu foi levantar dados que fornecessem subsídios em relação às dificuldades da prática dos professores para posteriormente ser proposta a Ginástica como um tema da Educação Física escolar, de acordo com as possibilidades reais apresentadas pela maioria das escolas atualmente.
\end{abstract}

Palavras-chave: Ginástica Artística. Ginástica Rítmica. Educação física escolar.

\section{INTRODUÇÃO}

A partir de diversos estudos (NISTA-PICCOLO, 1988; POLITO, 1998; BARBOSA, 1999; PAOLIELLO, 2001; AYOUB, 2003) que tiveram como foco de investigação as razões da ausência da prática da Ginástica na escola, realizamos uma pesquisa em instituições de ensino formal da Diretoria de Ensino de Campinas (SP), para verificar até que ponto o quadro diagnóstico encontrado é o mesmo desenhado pelas conclusões apresentadas nesses estudos. Ou seja, os conteúdos curriculares desenvolvidos nas aulas de Educação Física ainda não contemplam a prática da ginástica no ambiente escolar.

\footnotetext{
${ }^{1}$ Baseado na Dissertação de Mestrado O projeto "Crescendo com a Ginástica": uma possibilidade na escola, defendida em 2003 por Laurita Schiavon.

Mestre. Faculdades Metropolitanas de Campinas e Universidade São Judas Tadeu, Campinas SP, Brasil. E-mail: lauritaschi@hotmail.com

Doutora. Faculdades Metropolitanas de Campinas e Universidade São Judas Tadeu. Campinas, SP, Brasil. E-mail: vilmanista@usjt.br
} 


\section{Antigor Orifimais Laurita Schiavon e Vilma Nista-Piccolo}

As diferentes pesquisas realizadas apontam que o desconhecimento sobre como aplicar a Ginástica, por parte dos professores, é a principal razão apresentada, mostrando que esses profissionais têm dificuldades em visualizar essa modalidade esportiva além da sua perspectiva competitiva. Isto é, eles não sabem quais são as contribuições da aprendizagem dessa modalidade para o desenvolvimento motor de seus alunos.

Essa questão pode sugerir a existência de falhas na formação do profissional de Educação Física, relacionadas ao conhecimento da Ginástica como um fenômeno cultural que não se limita ao aspecto competitivo.

É provável que os conteúdos gímnicos desenvolvidos na graduação desses professores não consigam traduzir a realidade das escolas, deixando de preparar os futuros profissionais para solucionarem os problemas que possam encontrar no trato da Ginástica na escola.

$\mathrm{Na}$ verdade, ao analisarmos as grades curriculares dos cursos de Educação Física, em diferentes Faculdades, percebemos que falta um olhar pedagógico sobre essa modalidade esportiva; não há vivências que privilegiem o ato de ensinar Ginástica para crianças e adolescentes, nas quais se interpretem as dificuldades em trabalhar com o conteúdo gímnico.

Muitos cursos ainda não valorizam as práticas de ensino que podem acontecer fora da grade curricular, permitindo que os alunos vivenciem experiências significativas para o ato de ensinar.

Vivências extracurriculares e experiências de vida
anteriores ao ingresso no curso devem também ser
valorizadas. Creio que atividades fora da sala de
aula, formais ou informais, e principalmente
programas de extensão à comunidade que a imediata
dialética teoria-prática, devam ser fortemente estimu-
lados pelas instituições de ensino superior. (BETTI,
1992, p. 248).

Uma forma de reconhecer as dificuldades que possam surgir numa prática de Ginástica Artística (GA) e de Ginástica Rítmica

Movimento, Porto Alegre, v. 13, n. 03, p. 131-150, setembro/dezembro de 2007. 
(GR) para crianças na escola, é a criação de projetos de extensão, voltados para a comunidade, sendo desenvolvidos na própria Universidade. Projetos que tenham como objetivo maior ensinar o graduando a ensinar Ginástica, viabilizando, assim, futuras adaptações dessas modalidades aplicadas nas escolas.

O caminho escolhido neste estudo foi inicialmente a elaboração de uma pesquisa de campo envolvendo os professores de escolas públicas e particulares da rede de ensino de Campinas e região. Foram levantados dados que nos fornecessem subsídios em relação às dificuldades da prática dos professores para que posteriormente pudéssemos propor a Ginástica como um tema da Educação Física escolar, de acordo com as possibilidades reais apresentadas pela maioria das escolas atualmente.

Para isso, foi oferecido um curso experimental de 40 horas para esses professores, buscando oferecer subsídios básicos que complementassem sua formação em Educação Física. Os conteúdos desenvolvidos no curso estavam voltados para a construção de aulas de Ginástica na escola, com ou sem materiais. Posteriormente, auxiliávamos os professores na aplicação da Ginástica em suas práticas pedagógicas escolares, a fim de detectar as principais dificuldades que eles encontravam no desenvolvimento dessa modalidade.

Muitos professores que participaram do curso ficaram motivados em desenvolver esses conteúdos em suas aulas, e descobriram em suas escolas materiais novos (aparelhos ainda embalados com plásticos) que nunca tinham sido utilizados; descobriram "plintos" que serviam de mesa na secretaria da escola e ainda não tinham sido usados para sua finalidade.

Diante dos obstáculos apresentados pelos professores, ao ensinar GA e GR às crianças das escolas em que atuavam, foram elaboradas diversas adaptações de materiais, e foram criadas muitas sugestões de alternativas para as dificuldades destacadas nesta pesquisa.

Muitas das dificuldades declaradas estavam relacionadas ao conhecimento específico das modalidades gímnicas, ao método de trabalho e às estratégias de ensino. Mas, a impossibilidade de

Movimento, Porto Alegre, v. 13, n. 03, p. 131-150, setembro/dezembro de 2007. 
adquirir material adequado parecia ser a causa de maior impedimento da aplicação da ginástica na escola.

Este artigo descreve os caminhos para a detecção das dificuldades enfrentadas pelos professores de Educação Física no desenvolvimento das aulas de GA e GR no cenário escolar e mostra os resultados obtidos com a pesquisa.

\title{
2 DECISÕES METODOLÓGICAS
}

[...] é preciso buscar o caminho mais apropriado para alcançar o saber, e quando se trata de saber mais alto, o caminho ou circuito maior, já que o mais curto seria inadequado para tão elevado fim. (HÜHNE, 1995, p. 155).

A intenção deste trabalho é, principalmente, possibilitar a inserção da Ginástica na escola, portanto, não nos interessa conhecer os valores numéricos, ou a freqüência estatística de aplicação dessa modalidade, mas sim, entender quais são as dificuldades que os professores encontram para o desenvolvimento desse tema na realidade escolar, que muitas vezes os impedem de ensinar. Só a partir dessa compreensão é possível criar alternativas facilitadoras da aprendizagem dos elementos gímnicos nas escolas.

A preocupação deste estudo vai além, quando se volta também para uma questão da qualidade da Ginástica, quando inserida na escola, interpretando a maneira como este tema está sendo desenvolvido para as crianças. Assim, nossa pesquisa caminhou numa abordagem qualitativa. Chizzotti (2001, p. 79) esclarece que:

\begin{abstract}
A abordagem qualitativa parte do fundamento de que há uma relação dinâmica entre o mundo real e o sujeito, uma interdependência viva entre o sujeito e o objeto, um vínculo indissociável entre o mundo objetivo e a subjetividade do sujeito.
\end{abstract}

Neste percurso, o estudo vai se delimitando no decorrer de seu desenvolvimento, pois os fatos reais, as interações sociais fazem surgir as questões acerca do tema, ou seja, as dificuldades vão sendo

Mvimento, Porto Alegre, v. 13, n. 03, p. 131-150, setembro/dezembro de 2007. 
apontadas e, a partir destes dados, surgem as possibilidades de aplicação das propostas gíminicas para as reais condições.

Antes de se iniciar a pesquisa, de ir até o sujeito e ao seu ambiente, não se sabe o que podemos encontrar. Temos hipóteses dos acontecimentos, mas estas só se confirmam, ou não, no decorrer da pesquisa, o que muitas vezes pode nos levar para caminhos diferentes daqueles imagináveis no início da mesma.

\section{LEVANTAMENTO DE DADOS}

Foram utilizadas as técnicas de documentação direta e indireta no levantamento de dados do presente estudo. A documentação indireta pode ser feita de duas maneiras: a) pesquisa bibliográfica e b) pesquisa documental, que foram utilizadas neste estudo. Os arquivos e documentos analisados pertencem ao Projeto "Crescendo com a Ginástica" (PCG), um projeto de extensão à comunidade que foi desenvolvido na Universidade Estadual de Campinas (UNICAMP), durante dez anos, com o objetivo de oferecer aos graduandos em Educação Física uma oportunidade de aprender como ensinar Ginástica para crianças. Todos os documentos relacionados ao desenvolvimento desse projeto que foram armazenados puderam ser consultados para uma análise mais profunda. Os dados encontrados relacionavam-se:

- à preparação das aulas de Ginástica para as crianças;

- à preparação dos monitores (graduandos) que ministravam as aulas, por meio de cursos semestrais de formação técnicopedagógica;

- aos objetivos propostos nas atividades aplicadas;

- às observações feitas pelos monitores, nos planejamentos de aula;

- às observações dos professores responsáveis pelo projeto e anotações dos discursos das crianças que participavam do PCG.

Movimento, Porto Alegre, v. 13, n. 03, p. 131-150, setembro/dezembro de 2007. 
A documentação direta constitui-se no levantamento de dados no próprio local, onde os fenômenos ocorrem. Nesta pesquisa utilizouse a pesquisa de campo. Assim, investigamos os professores de Educação Física que participaram do curso que foi oferecido na Universidade, inteiramente grátis, que se dispuseram a aplicar Ginástica em seus conteúdos de aulas nas escolas.

O objetivo da pesquisa de campo visava conhecer a realidade das aulas de Educação Física, a fim de poder detectar quais as dificuldades encontradas ao aplicarem GAe GR no ambiente escolar. Procurou-se obter informações sobre os problemas causados por essa prática, buscando oferecer possíveis soluções para o desenvolvimento destas modalidades.

Os sujeitos analisados são professores de Educação Física de escolas das redes de ensino municipal, estadual e particular de Campinas e região. "Como sujeitos da pesquisa, identificam seus problemas, analisam-nos, discriminam as necessidades prioritárias e propõem as ações mais eficazes" (CHIZZOTTI, 2001, p. 83). Foi exatamente o que se buscou levantar nessa etapa da pesquisa de campo. Todo este estudo foi dividido em quatro etapas:

1) elaboração e o desenvolvimento de um curso preparatório para os professores de Educação Física das três redes de ensino de Campinas e região, com a intenção de subsidiálos em relação à aplicação da Ginástica na escola;

2) na medida em que os professores começavam a aplicar Ginástica em suas aulas, recebiam uma orientação, ocorrida posteriormente ao curso, ao longo de um semestre, como uma assessoria pedagógica;

3) foram feitas observações das aulas de Ginástica ministradas por esses professores;

4) foram realizadas entrevistas com esses professores com o intuito de se obter mais dados em relação a esta experiência.

Movimento, Porto Alegre, v. 13, n. 03, p. 131-150, setembro/dezembro de 2007. 


\subsection{ELABORAÇÃO E REALIZAÇÃO DO CURSO "CRESCENDO COM A GINÁSTICA"}

O objetivo desse curso foi o de oferecer subsídios aos professores para que pudessem desenvolver a prática da GA e da GR em suas aulas de Educação Física, e que, a partir dessa aplicação, analisássemos as dificuldades encontradas por eles.

$\mathrm{O}$ curso $^{2}$ foi oferecido gratuitamente aos professores nas dependências da Faculdade de Educação Física da UNICAMP, e foi baseado no curso de formação que era oferecido aos monitores do projeto "Crescendo com a Ginástica", a cada semestre. Foi elaborado com aulas práticas e teóricas, relevantes para o desenvolvimento da Ginástica numa perspectiva educacional, abordando os seguintes tópicos:

- apresentação do projeto "Crescendo com a Ginástica";

- a importância da GA e GR na formação da criança;

- questões motivacionais presentes nas aulas de Educação Física;

- o aspecto lúdico nas aulas de Educação Física;

- os padrões básicos de movimento da Ginástica;

- os conteúdos da Ginástica Rítmica e um paralelo com a teoria de César Coll;

- o método de ensino dos "três momentos", desenvolvido no projeto "Crescendo com a Ginástica", com suporte teórico em Vygotsky;

- aulas práticas de GR;

- aulas práticas de GA;

- orientação para planejamento de aulas de Ginástica para escola.

\footnotetext{
${ }^{2}$ Ministrado pelas professoras Dra. Vilma Lení Nista-Piccolo, Dra. Elaine Prodócimo, Dra. Myrian Nunomura, Dra. Marília Velardi, Ms. Eliana de Toledo, Profa. Ms. Suzana Koren e Ms. Laurita Schiavon.
}

Wovimento, Porto Alegre, v. 13, n. 03, p. 131-150, setembro/dezembro de 2007. 


\section{Antigor Orifimais Laurita Schiavon e Vilma Nista-Piccolo}

\subsection{DIVULGAÇÃO E INSCRIÇÃO NO CURSO}

A divulgação para a rede estadual foi feita por meio de convites e cartazes entregues às Assistentes Técnicas Regionais de Educação Física das duas regiões de Campinas. Para os professores da rede municipal, foi feita mais próxima à data de início do curso pela Secretaria de Educação de Campinas, devido ao prazo de aprovação da mesma. Já para as escolas particulares, o cartaz foi entregue pessoalmente em cada uma delas.

As inscrições foram feitas por telefone, e-mail ou diretamente no Departamento de Educação Motora da Faculdade Educação Física da UNICAMP, durante o prazo de um mês, utilizando-se como critério o limite de vagas, com o número máximo de 60 vagas. Esse número foi estabelecido por conta do espaço adequado para o recebimento destes professores, mantendo a qualidade proposta pelo curso. Foram preenchidas todas as vagas até o último dia de inscrição.

\subsection{REALIZAÇÃO DO CURSO}

O curso "Crescendo com a Ginástica" foi oferecido gratuitamente no período de férias escolares, de 9 a 14 de julho de 2001, totalizando 40 horas-aula, visando dar maior aproximação dos professores de Educação Física das escolas públicas e particulares de Campinas e região, oferecendo conhecimento básico de Ginástica escolar, de acordo com os tópicos citados acima na elaboração do curso. Durante as aulas práticas, tivemos a preocupação em desenvolver o próprio método de ensino que estava sendo ensinado, para posterior aplicação com seus alunos. Isto quer dizer que não foi transmitida apenas a técnica dos elementos da Ginástica, mas sim a forma como esses poderiam ser ensinados.

O curso foi realizado nas dependências da Faculdade de Educação Física da UNICAMP e efetivamente não foram todos os inscritos que compareceram, mas com a presença de 34 professores que participaram ativamente de todas as propostas, demonstrando estar sempre muito motivados e com vontade de aprender.

Movimento, Porto Alegre, v. 13, n. 03, p. 131-150, setembro/dezembro de 2007. 
Foi distribuído um questionário no início do curso para termos idéia do público que havíamos alcançado com a nossa divulgação, e qual o conhecimento e experiência de ginástica que possuíam. Além dos dados pessoais, foi perguntado onde lecionavam e há quanto tempo; se já haviam trabalhado com a Ginástica em seus conteúdos escolares; se tinham alguma experiência com a Ginástica antes de freqüentar este curso; se tinham interesse em aplicar este conteúdo em suas aulas; qual a expectativa em relação ao curso; se existiam materiais destas modalidades em suas escolas; e qual a disponibilidade de espaço que possuíam em suas escolas para o desenvolvimento de suas aulas.

Dos participantes do curso, havia sete professores que atuavam em escolas municipais, $18 \mathrm{em}$ escolas estaduais e nove em escolas particulares, sendo alguns profissionais recém formados e outros que lecionavam há muito tempo, alguns até mesmo com 30 anos de experiência, formando um público bastante heterogêneo. Poucos professores não tinham tido nenhuma experiência com GA e GR, e a maioria vivenciou essas modalidades, ou ao menos uma delas, durante seu curso de graduação. Muitos já haviam ensinado Ginástica nas aulas de Educação Física, mas, de acordo com as respostas apresentadas nesse primeiro questionário, observamos que ansiavam por maiores conhecimentos, e principalmente, como conquistar as crianças para essas aulas, buscando encontrar formas para deixar as aulas mais prazerosas e motivadoras. Além disso, os professores mostravam-se interessados em saber como adaptar materiais para as aulas de Ginástica em suas escolas.

Em relação a esse tópico, apenas quatro escolas não possuíam nenhum material específico, sendo duas escolas municipais e duas estaduais. Um terço das escolas possuía colchões, plintos, arco, bola, maça e/ou corda. E outros, ainda, citaram ter bastões, bancos suecos, fita, trampolins e trave de equilíbrio. Apenas um professor de escola estadual e outro de escola municipal disseram não ter espaço mínimo para o desenvolvimento das aulas.

No encerramento do curso, alguns professores demonstravam ainda mais interesse em aprender mais sobre ginástica. Isso

Movimento, Porto Alegre, v. 13, n. 03, p. 131-150, setembro/dezembro de 2007. 
mostrou que o trabalho desenvolvido com métodos próprios, estimulou a auto-motivação dos participantes, levando-os a perceber como é possível sentir prazer no aprendizado destas modalidades. Propostas ensinadas numa perspectiva lúdica, com finalidades educativas, as quais respeitam aspectos importantes da individualidade dos alunos, podem aumentar a vontade de aprender mais.

Foi feita uma avaliação do curso para compreender a importância que o mesmo teve para os professores, reconhecendo se as suas expectativas haviam sido alcançadas. Também foi possível detectar quais temas gostariam de se aprofundar mais, recebendo críticas e sugestões sobre todo o desenvolvimento do curso. Todos os dados foram computados e transformados em tópicos mais relevantes no olhar do pesquisador.

\section{ASSESSORIA PEDAGÓGICA}

A assessoria pedagógica oferecida aos professores interessados foi previamente agendada. Num primeiro momento, muitos professores ainda motivados com o que aprenderam no curso mostraram-se interessados em dar continuidade com a pesquisa, recebendo orientações para as suas aulas de Ginástica que seriam desenvolvidas nas escolas. Mas, efetivamente, poucos puderam comparecer na primeira reunião e assumiram o compromisso de encontros mensais, em busca do aperfeiçoamento de suas aulas.

A assessoria pedagógica se dava nesses encontros, que aconteceram durante todo o segundo semestre de 2001, nos quais buscávamos levantar as dificuldades para desenvolver aulas de Ginástica na escola. Muitas soluções puderam ser sugeridas pelos próprios participantes. Eram oferecidas e discutidas orientações sobre como trabalhar em escolas sem material adequado, ou mesmo com pouco material. Muitos momentos foram gastos com a elaboração dos planos de ensino, realizados sempre em grupos.

O objetivo principal desses encontros era proporcionar a troca de experiências, apresentando os problemas e oferecendo diferentes

Movimento, Porto Alegre, v. 13, n. 03, p. 131-150, setembro/dezembro de 2007. 
possibilidades de aplicação da GA e da GR em suas aulas, para dar maior segurança aos professores.

Os temas mais solicitados nesses encontros com os professores foram: os métodos de ensino da Ginástica; dicas sobre a elaboração de coreografias; uso de materiais alternativos ou adaptados; planejamento de aulas; discussões dos obstáculos encontrados nas aulas; apresentação de sugestões para resolução desses problemas.

Somente cinco professores conseguiram adequar seus programas curriculares à proposta de oferecer Ginástica em suas aulas e, portanto, se dispuseram durante os quatro meses seguintes, em sete escolas, a receber orientações para a aplicação dessa modalidade, discutindo suas dificuldades. Os dados coletados nessas assessorias foram registrados para interpretações gerais em forma de categorias.

\section{OBSERVAÇÃO DAS AULAS}

"A experiência direta é sem dúvida o melhor teste de verificação da ocorrência de um determinado fenômeno" (MENGA; ANDRÉ, 1986, p. 26). Após o segundo encontro com os professores, foram iniciadas as visitas às suas respectivas escolas, para a observação das aulas, verificando diversos tópicos adotados pelos professores. As características de observação utilizadas foram: sistemática, não participante, individual e na vida real (LAKATOS; MARCONI, 1986).

Estas observações aconteceram durante todo o segundo semestre de 2001, sendo em média uma vez a cada quinze dias, em cada escola, tendo como foco principal os seguintes tópicos:

- conteúdos de Ginástica desenvolvidos nas aulas de Educação Física;

- métodos de ensino das aulas de Ginástica;

- participação dos alunos;

- relação professor-aluno;

- infra-estrutura para as aulas;

Movimento, Porto Alegre, v. 13, n. 03, p. 131-150, setembro/dezembro de 2007. 
- apoio da direção da escola;

- motivação expressa pelos alunos nas aulas de Ginástica.

As observações foram todas registradas gravadas e posteriormente transcritas para o papel. Após o término de cada aula, surgia uma assessoria individualizada. As escolas cujos professores se interessaram no acompanhamento e na orientação do trabalho foram: três municipais, três estaduais e uma particular. As descrições das observações realizadas foram reduzidas em unidades de significado.

Como exemplo de dados observacionais da pesquisa na questão de infra-estrutura (materiais), temos:

- Apoio da direção da escola: foi possível notar que as escolas que tinham o apoio da direção, inclusive na participação das entrevistas dessa pesquisa de campo, prestigiando as apresentações que as crianças fizeram com a GA e a GR, elogiando os seus professores, enfim, cumprindo o seu papel de apoiar diferentes propostas educativas, tinham mais material e principalmente professores mais motivados para adaptar os materiais. Buscavam até mesmo emprestados de outro local, fazendo tudo possível para não deixar de oferecer essas modalidades. Já nas escolas em que a direção não foi sequer percebida no ambiente, os professores falavam da falta de apoio e estrutura da direção da escola, da falta de valorização do profissional, fatores que com o passar dos anos fazem minguar as forças dos professores idealistas que buscam desenvolver atividades adequadas aos seus alunos. Esses professores, após muitas dificuldades e sem respaldo algum da direção da escola, acabam desistindo, perpetuando o cômodo "trabalho" de apenas "dar a bola" aos seus "alunos" (SCHIAVON, 2003).

Sobre a questão do método de ensino ${ }^{3}$ que não apenas direcione a atividade, mas que explore as possibilidades de movimento e

\footnotetext{
${ }^{3}$ Para conhecimento detalhado deste métdo de ensino, consultar: VELARDI, Marília. Metodologia de ensino em Educação Física: contribuições de Vygotsky para as reflexões sobre um modelo pedagógico. 1997. Dissertação (Mestrado). Faculdade de Educação Física, UNICAMP, Campinas, 1997.
}

Mvimento, Porto Alegre, v. 13, n. 03, p. 131-150, setembro/dezembro de 2007. 
proponha a solução de problemas antes desse tradicional momento de direcionar atividades aos alunos:

- Transformar a rotina: observou-se na pesquisa de campo que os profissionais apresentam resistência e/ou dificuldades para modificarem suas rotinas de ensino (SCHIAVON, 2003).

- Outras formas de ensinar: no desenvolvimento das aulas foi possível notar o desconforto dos professores na aplicação desse caminho para ensinar, principalmente nos momentos em que a atividade não era totalmente direcionada. Apesar de implantarem o método com dificuldades, a prática de tantos anos de experiência de trabalho e de formação, voltada para métodos que direcionam a atividade por completo, fazia com que eles enfatizassem o terceiro momento da proposta metodológica e considerassem o direcionamento como a parte principal da aula.

- Adaptação a outras formas de ensino/aprendizagem: começar a implantar esse método requer paciência para que tanto professor quanto alunos adaptem-se às novas possibilidades e maneiras de agir em aula. Surgiram vários momentos de desconforto dos alunos quando solicitados para resolver os problemas apresentados; muitas vezes, eles pediam ao professor que lhes dissesse "o que fazer", pois tornava-se trabalhoso refletir para agir.

Sobre a terceira unidade de significado levantada, a questão de conteúdo das aulas:

- Procedimentos são os principais: os professores, na maioria das vezes, se preocupam muito com os conteúdos procedimentais e pouco com os conteúdos conceituais e atitudinais, o que gera alunos que estão sempre "fazendo alguma coisa" (ocupados), mas não sabem definir o que fazem, nem por que fazem. Algumas crianças após várias aulas não sabiam que estavam fazendo ginástica, qual o nome dos exercícios, dos elementos, etc. A compreensão dos alunos sobre o conteúdo da aula depende dos conceitos transmitidos sobre as modalidades, que em geral não são passados.

Movimento, Porto Alegre, v. 13, n. 03, p. 131-150, setembro/dezembro de 2007. 
144 Astigos Orifinais Laurita Schiavon e Vilma Nista-Piccolo

\section{ENTREVISTAS}

Foram realizadas entrevistas com os professores, caracterizando-se uma observação direta intensiva, ou seja, o uso de duas técnicas conjuntamente, a observação in loco somada às entrevistas.

Um dos aspectos importantes da observação direta intensiva é o fato de podermos levantar questões ainda não pensadas. Os problemas surgem durante as aulas, nos comentários espontâneos dos professores, muitas vezes na falta de coerência do discurso com a prática. Com isso, entendemos o contexto estudado, as dificuldades expressas pelos professores, gerando possíveis soluções para a atividade proposta.

O tipo de entrevista utilizada nesta pesquisa foi a despadronizada, ou não estruturada. Na modalidade entrevista, usamos a focalizada, na qual existe um roteiro de tópicos relativos ao problema e o entrevistador tem liberdade de fazer perguntas, não obedecendo a uma estrutura formal.

As entrevistas foram feitas nas escolas que participavam da pesquisa, após terem ocorrido no mínimo três aulas sobre o tema da ginástica, para que o professor já tivesse elementos de resposta em relação à aplicação dessa modalidade nas aulas de Educação Física.

Os temas abordados foram em relação ao conhecimento do professor sobre as questões da ginástica, anterior e após o curso, e quais as modificações feitas nas suas aulas a partir da realização do curso. Os dados levantados foram reduzidos em três categorias: conteúdo, método de ensino e infra-estrutura.

Alguns professores dessa pesquisa de campo, após conhecerem mais sobre a GA e a GR no curso que lhes foi oferecido, "descobriram" materiais dessas modalidades em suas escolas, que até então estavam "invisíveis" aos seus olhos. Motivados pelo aprendizado ou pela atualização de conhecimento recebida no curso, procuraram em suas escolas materiais que pudessem usar em suas aulas de Ginástica e alguns encontraram jogos completos de materiais "oficiais" de GR, ainda plastificados, guardados embaixo de outros materiais na

Mvimento, Porto Alegre, v. 13, n. 03, p. 131-150, setembro/dezembro de 2007. 
sala de Educação Física, abandonados por não se saber o que fazer com eles. Outro professor encontrou um plinto na secretaria da escola, com toalha em cima, sendo usado como mesa. Outros professores que tinham algum material, como colchão e plinto, passaram a usá-los, descobrindo maneiras diferentes de fazê-lo. Outros ainda buscaram construir ou adaptar os materiais envolvendo a comunidade da escola (SCHIAVON, 2003).

Por diversas vezes, os professores participantes da pesquisa falavam sobre o método, demonstrando o conhecimento do mesmo, mas no desenvolvimento de suas aulas faziam o que estavam acostumados, ou seja, direcionavam a atividade totalmente.

$\mathrm{Na}$ GR, os professores trabalhavam muito com a exploração dos aparelhos, o que é muito rico e importante no desenvolvimento do trabalho, mas não sabiam o que oferecer de conteúdo procedimental às crianças para que as mesmas continuassem seu desenvolvimento ao tema proposto, isto é, elas não saem da primeira fase de exploração, e atribuem isso ao desconhecimento do conteúdo (SCHIAVON, 2003).

\section{RESULTADOS}

As técnicas desenvolvidas nessa pesquisa de campo (questionários, avaliações, assessoria pedagógica, observações e entrevistas), somadas às outras formas de contato com os professores, serviram para desvelar as reais dificuldades da aplicação dessas modalidades na escola.

Os problemas levantados a partir da coleta dos dados possibilitaram uma análise interpretativa na essência da pesquisa. Esses dados foram pontuados criteriosamente e interpretados, não se perdendo o foco das dificuldades que os professores encontraram para desenvolver a proposta de GA e GR na escola.

Após as descrições, caminhamos para a redução dos dados. O primeiro momento de análise foi elencar unidades de significado. Na busca de sintetizar as unidades de significado, elencadas a partir

Movimento, Porto Alegre, v. 13, n. 03, p. 131-150, setembro/dezembro de 2007. 
da leitura da descrição de todos os dados, foi possível perceber que havia uma convergência para três grandes categorias:

- Infra-estrutura, espaço e materiais: fator bastante levantado pelos professores nos questionários e entrevistas, e observado nas aulas de ginástica nas escolas. Existe um grande interesse por parte dos profissionais em relação à solução desses problemas e é uma das razões da falta de motivação dos profissionais em desenvolver a GA e a GR na escola.

- Método e estratégias de ensino: aspecto citado nas entrevistas e nos questionários. Os professores afirmavam não saber "como" ensinar determinados elementos gímnicos. Ficou muito clara a dificuldade que alguns professores apresentam em criar instrumentos de ação pedagógica, isto é, não são capazes de elaborar meios facilitadores da aprendizagem de determinados elementos. E ainda, têm dificuldade na organização das aulas de Ginástica, quebrando paradigmas em relação aos métodos tradicionais de treinamento esportivo. Percebemos que isso gerou, muitas vezes, a ausência de motivação por parte dos alunos e, conseqüentemente, do professor.

- Conteúdos da ginástica artística e da ginástica rítmica: esta foi a principal dificuldade apresentada pelos professores, pois desconhecem os conteúdos procedimentais das ginásticas. Os professores não conseguem oferecer diferentes possibilidades de aprendizagem para que os alunos possam atingir níveis mais complexos. Não enxergam outros conteúdos além dos procedimentais, ou melhor, não percebem como conteúdos conceituais poderiam facilitar a compreensão de um movimento.

\section{DISCUSSÃO}

A pesquisa, na sua totalidade, buscou atender diretamente os profissionais que atuam nas escolas, cuja prioridade foi a concretude das sugestões apontadas, tornando-as disponíveis para auxiliar na

Movimento, Porto Alegre, v. 13, n. 03, p. 131-150, setembro/dezembro de 2007. 
aplicação destas modalidades gímnicas a serem inseridas ou aprimoradas nas aulas de Educação Física. Para isso, além de buscar respostas em livros, fomos concretizá-las nas próprias aulas de GA e GR. Compreendendo e analisando tanto as dificuldades como a realidade escolar, conseguimos, a partir dessa pesquisa, encontrar alternativas viáveis para as aulas de GA e GR no ambiente da escola.

O contato com os professores trouxe-nos a percepção do quanto nos afastamos dessa realidade que eles vivenciam nas escolas, e, muitas vezes, não imaginamos o quanto os profissionais desconhecem o trabalho com essas modalidades. Foi muito importante saber o que realmente faz falta na prática desses profissionais.

Entre os problemas e dificuldades apresentadas por eles, a questão dos materiais ou mesmo a falta deles é sempre apontada como fator principal. Mas, não basta a sugestão de materiais adaptados para que a ginástica torne-se mais viável nas escolas. Outro fator declarado pelos professores é a falta de conhecimento do conteúdo de cada modalidade. Nesta pesquisa foi possível perceber que mais importante do que solucionar o problema de falta de material é capacitar e trocar conhecimentos com os professores. Quando o professor tem o conhecimento do conteúdo a ser ensinado e de como deve ensinar, pode transformar suas idéias em uma prática possível, inclusive criando alternativas de materiais. $\mathrm{O}$ mesmo não acontece quando o professor tem materiais, mas não tem conhecimento dos conteúdos a serem ensinados (NISTA-PICCOLO, 1988; POLITO, 1996).

Portanto, é necessário capacitar os profissionais, não só oferecendo conhecimentos técnicos relacionados aos conteúdos dos diferentes temas da Educação Física escolar, mas criando possibilidades de transformação dos conhecimentos para a escola, de acordo com as suas realidades.

As modalidades gímnicas, em geral, não foram praticadas pelos professores em suas trajetórias acadêmicas, por não serem tão comuns quanto outras, fazendo com que eles tenham que se dedicar mais para buscarem atualizações.

Movimento, Porto Alegre, v. 13, n. 03, p. 131-150, setembro/dezembro de 2007. 
A falta de material também torna o cotidiano do profissional mais trabalhoso, pois precisa providenciá-lo, emprestá-lo (como pude presenciar na pesquisa de campo), e até mesmo fabricá-lo.

Quando se possui o material, é preciso carregá-lo, montar e desmontar, o que também gera mais trabalho para os profissionais, diferente de apenas carregar bolas. Quando acrescentamos desenvolvimento de aulas com métodos diferenciados e adequados à formação da criança, tudo fica ainda mais difícil. Não se pretende com esse discurso desencorajar o professor em relação à prática da Ginástica, mas salientar que o bom profissional tem muito trabalho para dar boas aulas de basquetebol, futebol, dança, lutas, assim como ginástica. Boas aulas requerem tempo de planejamento, estudo, atualizações, boa vontade, motivação, justificativas, enfim, a nossa profissão precisa de professores que além de gostarem de esporte, gostem de ensinar, pessoas que estejam sempre em busca de aprender um pouco mais e de experimentar algo novo, assim como os professores que se dispuseram a fazer parte desta pesquisa de campo.

Gymnastics at school
Abstract: Based on studies which focus on the
investigations of the reasons for the absence of
gymnastics at school, a research in institutions of
formal tutoring under the Board of Education of
Campinas, SP, was done in order to verify the
proximity between the findings and the conclusions
presented in such studies. The goal was to bring
up data which could provide information on
teachers' teaching difficulties, to further suggest
Gymnastics as an academic Physical Education
subject, according to the real possibilities identified
in the majority of the current schools.
Keywords: Artistic Gymnastic. Rithimic Gymnastic.
Phisical Education.

Movimento, Porto Alegre, v. 13, n. 03, p. 131-150, setembro/dezembro de 2007. 


La gimnasia en la escuela
Resumen: A partir de los estudios que discuten
las razones de la ausencia de la Gimnasia en la
escuela, se ha realizado una investigación en
instituciones de enseñanza formal de la Directoria
de Enseñanza de Campinas-SP, para analizar has-
ta que punto el cuadro encontrado es el mismo que
el señalado por las conclusiones presentadas en
estos estudios anteriores. El objetivo fue recopilar
datos que ofrezcan indicadores respecto a las
dificultades de los profesores para proponer la
Gimnasia como un tema de la Educación Física
escolar, de acuerdo con las posibilidades reales
presentadas por la mayoría de las escuelas de la
actualidad.
Palabras clave: Gimnasia Artística. Gimnasia Rít-
mica. Educación Física.

\section{REFERÊNCIAS}

AYOUB, E. A Ginástica Geral e Educação Física escolar. Campinas: UNICAMP, 2003.

BARBOSA, I. P. A Ginástica nos cursos de licenciatura em Educação Física do Estado do Paraná. 1999. Dissertação (Mestrado) - Faculdade de Educação Física, UNICAMP, Campinas, 1999.

BETTI, M. Perspectivas na formação profissional. In: MOREIRA, W. W. (Org.). Educação física \& esportes: perspectivas para o século XXI. Campinas: Papirus, 1992.

CHIZZOTTI, A. Pesquisa em ciências humanas e sociais. 5. ed. São Paulo: Cortez, 2001.

HÜHNE, L. M. Metodologia científica: cadernos de textos e técnicas. 6. ed. Rio de Janeiro: Agir, 1995.

LAKATOS, E. M.; MARCONI, M. A. Fundamentos de metodologia científica. 21. ed. São Paulo: Atlas, 1986.

MENGA, L.; ANDRÉ, M. E. D. A. Pesquisa em educação: abordagens qualitativas. São Paulo: Editora Pedagógica Universitária, 1986.

NISTA-PICCOLO, V. L. Atividades físicas como proposta educacional para $1^{\text {a }}$ fase do $1^{\circ}$ grau. 1988. 177f. Dissertação (Mestrado) - Faculdade de Educação, UNICAMP, Campinas, 1988.

Movimento, Porto Alegre, v. 13, n. 03, p. 131-150, setembro/dezembro de 2007. 
PAOLIELLO, E. A Ginástica Geral e a formação universitária. In: FÓRUM INTERNACIONAL DE GINÁSTICA GERAL, 1. Campinas, 2001. Anais... CampinasSP: SESC: Faculdade de Educação Física, UNICAMP, 2001. p. 25.

POLITO, B. S. A Ginástica Artística na escola: realidade ou possibilidade. 1998. Monografia (Graduação) - Faculdade de Educação Física, UNICAMP, Campinas, São Paulo, 1998.

SCHIAVON, L. M. O projeto "Crescendo com a Ginástica": uma possibilidade na escola. 2003. 182 f. Dissertação (Mestrado) - Faculdade de Educação Física, UNICAMP, Campinas, São Paulo, 2003.

Movimento, Porto Alegre, v. 13, n. 03, p. 131-150, setembro/dezembro de 2007. 